\title{
Language and Sexuality in South Korea: A Case Study
}

\section{Mathew Bumbalough}

\begin{abstract}
This case study examines the language and sexuality of a gay man living in South Korea, exploring current literature, theories, and interview data as a way of investigating sexuality as a marker of identity. I define sexual identity in this case through the subjective reality of the participant as he expresses his 'true' self in the lived experience of his travels to different countries and speaking multiple languages. The aim of this study then is to analysis the discourse using Philip and Jorgensen's (2002) method of critical discourse analysis from a single interview to see how pronoun selection, language selection, speech intonations and inflections in his speech to see how it informs current research in Korean Studies and gender discourses.
\end{abstract}

Keywords: discourse analysis, sexuality, language, culture, South Korea

\section{Introduction}

Scholars have been taking note of issues of gender, sexuality, and language for quite some time (Bucholtz \& Hall, 2004; Cameron, 2005; Cameron \& Kulick, 2003; Norton \& Pavlenko, 2004 for example), but there is still quite a lack of research using discourse analysis (DA) to analyze this topic. While critical DA (CDA) has attempted to take up the mantle of responsibility for social empowerment of participants in studies, there is still some confusion about where this topic fits in to the large landscape of DA work. Additionally problematizing the issue is the focus on heteronormative (sexuality as reducible to heterosexuality) research which depends on reducing linguistic and language habits to a set of rules where these topics are often times ignored. As well, much of the research is still stuck in conversations around larger, more generalizable, data sets with quantitative analysis that seeks to normalize language into tidy neat packages. Furthermore, since most work in sexuality and language come from a Western perspective, there is a great need to studies that examine the nuances of sexuality and language from non-Western participant. King (2008) was one of the first western researchers to examine sexuality and language in Korean participants, and he shows how the marginalization of his participants in Korean society based on their sexuality limited their exposure to the LGBTIQ (lesbian, gay, bisexual, transgender, intersex, and questioning (henceforth: queer)) communities that are fairly common in Western society, shaping their experiences into something not quite resembling Western notions of sexuality. 
What this study hopes to accomplish then is to examine the discussion of sexuality and language in a CDA framework focused on identity as a discourse marker of language; further exploring King's work where the participant is both able to tell their story. What's more, I hope in the future to explore other studies of sexual identity in current Korean studies to see how King's notion of marginalization and limited access to queer communities affects language use in practice.

\section{Literature Surrounding Language and Sexual Identity}

It is important to first of all examine some of the recent literature surrounding language and sexuality before moving further. King (2008) conducted a study in which he provides a qualitative analysis of three South Korean gay males to see how they use English in naturalistic settings. While he does not have a concrete set of research questions, he explores the impact of Western-centric heteronormative thought on the real-life interactions of his participants. The participants themselves had widely different views on what it meant to be gay in Korea, and they all described the impact that traditional Korean culture had on them expressing their sexuality. All of the participants agreed that Korean culture did not encourage relationships that went outside the 'traditional' man-woman relationships, and many of them were using English as a means of finding community from without their society.

King uses the term 'imagined communities' to describe how they interacted with other speakers of English to build their social networks. Anderson (1991) was the first to describe what an imagined community is, and while he focuses on the nation-state as an example, King uses it to describe the gay community in Korea as existing only in the minds of his participant, with the intent on joining the community to express solidarity (even if they don't know any other gay males in South Korea). So, the queer community in Korea, such as it is, is more of a social construct, relying on poststructuralism to describe the amorphous nature of a community that is an idea, and not reality. I focused on King's study the most as it is similar to mine, but the methodology relies mostly on narrative inquiry and not CDA as total package of analysis. I therefore seek to further this work into the realm of CDA studies.

\section{Sexuality in Western Cultures}

Many studies have also examined the discourse surrounding sexuality in queer communities (Eckert \& McConnell, 1992; Jacobs, 1996; Blackburn, 2005; Huffaker \& Calvert 2005, for example), but much of this work focuses on the qualitative nature of language to provide generalizable results surrounding the words and intonations used in queer communities, and not necessarily on using sexuality as a marker to describe language in use. Bucholtz and Hall (2004) noticed this in their research and call for a theoretical "desire centered view" of identity (similar to Cameron and Kulick's) that takes into consideration social subjectivity which would describe identity as not something objective (free from individual influence), but highly contingent upon the desire of a subject to belong to a certain group.

The idea of subjectivity brings to mind the theory of 'otherness', defined by Duff and Uchida (1997) as objective stereotypes about identity. Otherness would then conflict with 
the subjectivity that Bucholtz and Hall describe, where come of the current research seeks to define language and sexuality as a set of rules that whole groups would fall into, while ignoring the individual and his or her desires. This research could be described as part of the academic or linguistic capital that researchers have when defining queer communities, described by Bourdieu (1991) (in terms of sexuality) as "the adoption of the dominant style is seen as a denial of social and sexual identity, a repudiation of the virile virtues which constitute class membership" (p. 88). However, in the queer community, linguistic capital could take a very different form, with members of the community using those infections, words, and pronunciations in order to fit in to the larger queer community.

While Bucholtz and Hall see current trends in language and sexuality studies as focusing on sexuality removed from desire and call for a focus on social subjectivism, King calls for a type of 'strategic essentialism' (p. 235) that seeks to examine sexuality as a marker of identity, but not reflective of the participant's identity as a whole. Foucault (1978) would agree somewhat with this notion as he sees identity as "neither uniform not stable" (p. 100). But how can researchers approach the issue of sexuality and language without becoming essentialist, and also taking into consideration the continual shifts and evolution of identity? Norton (2000) defines identity as immersed in language and society, and as one changes, so does the other. So, as a reflexive statement, sexuality becomes but one lens to view identity, and therefore language and society.

\section{Sexuality in South Korea}

Describing the current state of views of sexuality in South Korea is somewhat difficult to do. Most research still approaches the topic with Western ideology and is difficult to escape, which is why this literature review examines several Western studies. Dong-Jin (2001) provides a good start for reading about public and governmental views of sexuality, but since his article much has changed, with popular culture (movies, TV shows, and music) contributing toward less dogmatic stances. Despite the emergence of popular stars and icons who are now 'out' (revealing their sexuality) much of the discussion on sexuality has had a negligible impact on laws and Confucian views on what constitutes a family. Dong-Jin postulates that the absence of laws and public discourse on sexuality is simple a part of a bigger pattern that ignores homosexuality as having little to no impact on day to day life (p. 67). One thing to note is that while discrimination against homosexuality became illegal in 2006, it was later repealed in 2007 after interest groups protested the law. As a result, both Dong-Jin and King notice that the lack of attention queer communities in Korea receive has led to an import of Western thoughts and ideas by the fledgling queer communities to grasp on to a culture that is lacking in South Korea. They both also comment that many of the Western words used to describe homosexuality in the West (gay, butch, femme, etc) are used by these communities and are now part of the standard lingo used to describe each other (p. 76). Aside from Western words, social media has also played a large role in shaping these communities, with sites like buddy79.com and queerkorea.org offering both English and Korean functions to their members. In fact, it is easy now to find gay bars and people who adopt Western ideologies as a means of expressing their self. 
Despite this, Dong-Jin, through his research found that there is still a high amount of dissatisfaction with queer communities in South Korea. Most of this stems from the fact that being homosexual in Korea is still viewed by many as being deviant. A poll conducted in 2013 found that $39 \%$ of South Koreans believed homosexuality could be accepted in South Korean society; compared with only 18\% in 2007 (Ipsos, 2013). While this might show an upward trend, it still reveals that there is still quite a way to go with acceptance of queer rights. Most of this still stems from the fact that South Koreans are expected to marry and have children, and even those who are homosexual are pressed into doing this to continue their family line. Also, the queer communities in South Korea are still relatively small, and many do not wish to participate as it might ostracize them from others. Dong-Jin says that this might be a result of the Confucian ideals of the East competing with Western ideals of queer right; a social conundrum where it is easier to be 'stereotypical' than to try and create or join an queer community (p. 78).

Outside of laws, public perception, and the conflict between Western and Eastern thought, there is also a lack of Korean research from universities of higher education which focus on homosexuality. Most of the research that I found was written by South Korean with the intent of publishing in Western journals, while Korean language research is difficult if not impossible to find because of pay walls and the need to have a Korean ID to access many Korean educational journal sites. So we are stuck with research usually set in a Western paradigm that ignores Eastern thought. Many questions remain then of how to define sexuality in South Korea. How to those on the spectrum of sexuality perceive themselves? How do they connect with and join groups when there is such a push-back from society? I believe these questions will help to show just how difficult it is to research a topic without much empirical evidence to rely on.

\section{Defining Identity}

I find myself drawn to Norton's (2013) notion of identity as bound in relations of power, continually in flux and shifting depending on time and place. By focusing on sexuality in particular, I noticed how much power does come into play in language choice and expression of self, either hiding sexuality from the participant's Korean friends or family, or bragging about dates in English to his Western friends. Overall, I felt that the informal interview helped to, as King (2008) notes; encourage relating experience with the language in practice. I therefore use the term identity 'marker' in this case as the instances within the discourse that relate to the participants sexuality.

Benwell and Stokoe (2006) would define this identity broadly as "an 'essential', cognitive, socialized, phenomenological or psychic phenomenon that governs human action" (p. 3). This identity may be hidden from public view, or come out when around certain people are around to show their 'real' self. This identity would also determine what they do in certain situations; for example someone might draw on their religious identity when attending a synagogue, but then go out for pizza with graduate friends afterwards, drawing on their identity as a scholar or friend while the religious might take back seat. So, I view identity as constructed differently in different spaces, and should find that the social makeup of different groups will determine which identity is expressed. 


\section{Sexual Identity}

Jackson (2014) says that sexual identity is "how one thinks of oneself in terms of who one is sexually and romantically attracted to" (p. 147). This definition, while simplistic, is used by scholars in the field when describing sexuality. However, it can go further than simple romantic attraction, and argue (as have others) that sexuality is more of a spectrum, where some individuals might not feel sexual attraction at all. This definition then is too simplistic, and adds more to the heteronormative view of sexuality as a dichotomy (i.e. 'normal' vs. homosexual) than something which is very individualistic and part of a changing identity.

Others offer a more nuanced definition with Cameron and Kulick (2003) defining sexuality as not simply romantic attraction, but also; what they desire to do, how they define themselves, and the cultural and historical practices of which they are a part of (p. 89). King (2008) also takes their view of sexuality, but also finds that it is important to examine how the English words used in the queer community go across the Pacific and are used in Korean queer communities as well. Words like queer, gay, and lesbian are used by these communities as a way of identifying themselves, with the native Korean words still holding some negative connotations. King looks as sexuality through a poststructuralist lens where sexual identity is only one small part of the identities of his participants, continually evolving as they socialize with others (p. 232-233). So words that still might hold some negative connotations in the West (i.e. queer (until recently), dyke, homo) are used by Koreans to describe themselves, and are used much more freely by the Korean queer communities. My own lens then views sexual identity as but one small discourse marker (defined as words being said connected to the larger whole) to examine the larger phenomenon of English use by Koreans as they explore their sexuality in conversation.

\section{Theoretical Perspective}

Theoretically, I situated my study within a CDA framework (Phillips \& Jorgensen, 2002), seeking to understand how sexual identity is apparent in the spoken conversation with my participant. As the study is situated around one conversation, I felt that this framework fits in the best with this case study. Phillips and Jorgensen describe CDA as "empirical study of the relations between discourse and social and cultural developments in difference social domains" (p. 60). They also provides five common features that researchers use to approach CDA work (p. 5):

1. The character of social and cultural processes and structures is partly linguisticdiscursive

2. Discourse is both constitutive and constituted

3. Language use should be empirically analyzed within its social contexts

4. Discourse functions ideologically

5. Critical research

In this study I examine the spoken conversation in an informal interview as discourse data that can be applied to similar studies that examine sexual identity as a discourse marker, therefore staying mostly within features 3-5, but also pays attention the linguistic function of discourse markers. 


\section{Method}

\section{Research Questions}

The purpose of this case study is to explore the markers of sexual identity in the English language use of a South Korean male through a CDA of a semi-structured interview discussing his language regarding his sexuality. I pose the following questions in order to guide my data collection and analysis:

1. How does the participant use his languages (Korean or English) in expressing his sexual identity in conversation?

2. Does the participant's discourse markers match up with the social and cultural realities current studies explore related to sexuality in South Korea?

\section{Participant}

This case study follows one participant, Kris (pseudonym), who identifies as a homosexual male living in South Korea. I met Kris during my time spent in South Korea as a translator and administrator for public schools in Seoul. I have remained in contact with him for the past four years since my departure from Korea on social media and through emails. Kris came out to me several years ago and I was fascinated with the pressure that he felt from Korean society to remain 'in the closet' (hiding his sexuality) from his family and many of his close friends. I also noticed that he was more likely to come out to people from Western countries, and he maintained several relationships only with Westerners both in Korea and when he traveled overseas. He is now 27 years old and still living with his family near Seoul, having just come back from an internship in Australia, with plans to return overseas in the near future. He graduated with a BA in Romanian and Linguistics after a two year break to fulfill his military service, and has also traveled to many European countries. Aside from Korean and English, he also speaks Romanian and Italian.

\section{Data Samples}

Since I am interested in examining sexuality as an identity marker, I conducted a semistructured interview (in English) with my participant in the Fall of 2014 through Skype. I then transcribed the interview using Jeffersonian Transcription, paying special attention to intonation and inflection, as well as the pauses between questions and responses, as well as pauses in the responses themselves. During the interview, I focused on the languages he speaks, as well as which language he felt more comfortable with in expressing his sexuality. Since language and culture cannot be removed from each other, we also discussed which countries he has lived in and his experiences in expressing his sexuality in each of these cultures.

\section{Analysis}

In order to conduct discourse analysis using CDA I focused on the relevant excerpts from transcript data from the interviews and grouped them into thematic units using Creswell's (2008) method of thematic analysis. As I compiled and analyzed my data, I took note of the following in relation to sexuality as an identity marker: 
- How sexuality is expressed in English throughout both texts

- How images and postings reflected sexual identity

- How the participant negotiated his 'Korean-ness' while living in Western countries

- How the participant defined his own sexual identity

- How the participant negotiated relationships; and

- How the participant described English as a language of power

I present my findings around four wide-ranging themes that I noticed in the data; 1) The role of language choice in expressing sexuality; 2) expressing sexuality in different cultures; 3) making relationships; and 4) language and power.

\section{The Role of Language in Expressing Sexuality}

To begin, I examined how Kris talked generally about using different language when expressing his sexuality within the interview. Overall, I found that while Kris was a native speaker of Korean, he felt most comfortable talking about his sexuality in English, both in the language and in Western cultures, which shows that speaking English for him acts as an identity marker when showing his 'real' self to others who also spoke English or were in Western cultures. I was especially interested in how he navigated his sexuality when talking about his Korean family and acquaintances; hiding it from them and being very explicit that his sexuality was a 'taboo' subject that he would never bring up in Korean or with Koreans with whom he was not familiar.

I first brought up the topic of languages when expressing sexuality further into the informal interview, making sure that he felt the conversation was a safe space where he could talk without fear of really expressing his sexuality. In the conversation then, sexuality as identity didn't really come up until later on until we both felt comfortable with each other and how we would engage in a frank conversation surrounding, what was for him, a topic that is continually shifting and changing depending on the language and culture. Therefore, language expressing sexuality in an Eastern context is supported by the existing literature from King (2008) and Dong-Jin (2001) as exemplified by Extract 1.

\section{Extract 1}

In regards to sexuality:

[00:27:37.02] Kris: Hmm:: (1.0) well:: (1.0) >0k so speaking about like< (.) uh (1.0) like (.) sexuality $\uparrow$ $(1.0)$

[00:27:48.04] Interviewer: Hmmhmm.

$(.5)$

[00:27:48.04] Kris: In Korean (.) is kind of like $\downarrow$ taboo in society (.) $\downarrow$ You don't= you rarely talk about these things

$(1.0)$

[00:27:54.13] Interviewer: Ok

$(.5)$

[00:27:55.13] Kris: But in English $\uparrow$ I think that it's much more common and people talk about (.) talk about it much more freely $\uparrow($.$) So (.) um (1.0) yea (.) so those are (.) topics (.)< that's kind of >$ (.) um (.) That I rarely talk in Korean $\uparrow$

$(1.0)$

[00:28:11.28] Interviewer: Ok 
$(.5)$

[00:28:12.29] Kris:> I don't really talk about like sexes or like sexuality or like someone's sex Like<

(.) > Or you know just anything related to sex in Korean< (.) it's just really: (.) I don't really talk about it.[Like]

[00:28:22.19] Interviewer: [Ok]

$(.5)$

[00:28:22.19] Kris: So: (.) Yea >but in English I think that I have< had uh (.) lot of (.) chances to speak about them $\uparrow$ when I'm with my friends or [whatever]

[00:28:34.12] Interviewer: [Right]

[00:28:34.12] Kris: when I'm meeting someone (.) So (.) yea (.) I think that's (.5) the difference $\downarrow$

In Extract 1, Kris constructs language as indicative about what he will or won't talk about in Korean versus English. He follows with a general example about what he will not talk about specifically in Korean, saying that sexuality is a taboo subject and not up for discussion. However, when speaking English he feels as though he can talk about this topic with friends. The word 'taboo' was used later on in other parts of the conversation, always when talking about what not to say in Korean specifically, while the word 'blunt' was used more often when talking about English when discussing sexuality. Also, it is interesting to note the use of the pronoun 'you' when talking about Korean when expressing sexuality, and ' $I$ ' when talking about English, perhaps indicative of giving general advice to the interviewer about how 'proper' Koreans should act, or how a visitor to the country should act when talking about sexuality. Throughout the interview data the theme of using the pronoun 'you' when Kris described sexuality in Korea was most apparent, showing how he hid his own sexuality from others, and when using English he used the pronoun 'I', reflecting his non-hidden, perhaps more 'real' identity to Western speakers of English.

Further exploration of the link between languages and expressing sexuality were apparent earlier on in the conversation, as noted in Extract 2.

\section{Extract 2}

[00:21:00.22] Kris: Um (.) I think that um (.) because Korean and English $\uparrow($.$) these are two$ completely different language $\uparrow$. So (.) when I:: uh (.) learned English (.5) it kind of $\uparrow$ gave me the feeling that I can (.) express things really (.) straight-forward $\uparrow(.5)$ without really beating around bush=Because in Korean (.5) I think $\uparrow>$ it's kind of like like a little< bit social (.) atmosphere or whatever because um there too many (.) polite forms (.) and too many different ways of saying stuff in [Korean]

[00:21:36.27] Interviewer: [ Right].

[00:21:37.07] Kris: So times it gets really difficult for me to speak the (.) speak the things I want $\uparrow$ when I'm speaking with the person that $>$ I just met= or like when I'm speaking with $<$ (.) like(.) older:: (.) guys or whatever

[00:21:51.28] Interviewer: Yeah

[00:21:52.04] Kris: So (.) but English(.) it's just simple. Like (.) you just say:: (.) >I mean of course< there are also polite ways of saying (.) things in English (.) Like please sir (.) ma'am (.) whatever (.) But (.) like other $\uparrow$ than that you just say (.) the on- you know (.) There's no like (.) You don't really have to twist it around. $\downarrow$ It's just the same I guess. So::

$(1.0)$

[00:22:16.24] Interviewer: Ok.

(1.0) 
[00:22:16.24] Kris: Um (.) yea so I think that it's kind of: (.) I (.) like (.) I guess I learned (.) the way (.) I want to speak things (.) much more um (.) um (.5) bluntly $\uparrow$ I[guess] $\uparrow$

In extract 2, Kris compares English and Korean specifically. When describing Korean, he focuses more on Korean society as a means of expressing sexuality, while English is more about the words. Politeness studies in Korean is a major theme of research, where verb endings in speech determine the level of politeness when talking to others, whereas English does not have this linguistic feature. The use of the pronoun 'you' in this context when describing English compares the interviewer's speech to Kris's speech, describing the cultural differences of English. The use of the words 'straight-forward' and 'bluntly' further help to show the differences between English and Korean, with words like 'polite' and 'difficult' used to describe talking about sexuality in a Korean context. Therefore, the use of English in expressing sexuality and identity are more apparent and open than expressing the same concepts in Korean, further matching up with existing literature. Extract 3 confirms this sentiment as seen below.

\section{Extract 3}

[00:34:39.00] Interviewer: Yeah (.) So as far $\uparrow$ as expressing your (.) your sexuality then (.) which language and culture do you feel most comfortable doing it in? $\downarrow$

[00:34:47.08] Kris: Um (.) I think that English is more: (.) is (.) is really easy $\uparrow($.$) Cause (.5) I don't$ know like (.) I think that (.) like (.) $>$ I don't know<= For me I (.) use English the most whenever I: (.) talking about this stuff (.) this stuff $\uparrow$

(.)

[00:35:09.16] Interviewer: Ok

(1.0)

[00:35:09.16] Kris: I rarely $\uparrow$ talk about this when I was speaking Korean or when (.) I don't know like in other languages $\uparrow$ (.) So I think that English much more (.) easier (.) and comfortable for me to talk about my sexuality.

Extract 4 is interesting when examining inflections and intonations. When speaking about English, Kris talks more quickly and freely, with words like 'easy' and 'stuff' (in regard to sexuality) rising in intonation, reflecting that English is indeed more comfortable for him to speak about the topic of sexuality. However, when talking about Korean when expressing sexuality, the word 'rarely' is highly inflected and the intonation rises, symbolizing how Korean is not used to discuss sexuality. As well, the speed with which he talks about Korean language and expressing sexuality is much slower, with his response coming quicker after the question by the interviewer, showing how it is imperative that Korean is not conducive to expressing sexuality.

Overall, the data surrounding sexuality and language in use shows that English is more favorable when expressing sexuality, whether the speaker was in Korea with English speaking friends, or outside of Korea with English speaking friends. As such, the use of language in different cultures became the next topic we discussed.

\section{Expressing sexuality in different cultures}

The next part of the informal interview focused on expressions of sexuality both inside and outside of Korea. Much of what I found is that Kris's experience matches up with 
what King (2008) describes as a dissatisfaction with the queer community in Korea (p. 241), and what Dong-Jin describes as the borrowed culture from the West which helps to shape the imagined queer community in South Korea (p. 70). Extract 4 revolves around expressing sexuality in South Korea.

\section{Extract 4}

[00:29:37.00] Interviewer: Alright (.) What was there like someone you would tell (.) like would you (.) a-as far as language goes then (.) were there certain groups of people (.) who you would tell $\uparrow($. and certain groups that you wouldn't tell about your sexuality or would you just kind of (.) only told specific people?

[00:29:48.27] Kris: Uh:: (.) I:: =need (.) definitely would never (.) Like I don't really talk like (.) I would never and ever (.) tell my sexuality to someone (.) like elders $\uparrow$ in Korea (.) Korean elders $\uparrow($. Because they are: really conservative (.5) But I usually $\uparrow>$ talk about my sexuality now really freely< $<$ when I'm with my friends $>$ (.) W-With my Korean friends=Like if (.) like if (.) they are really close to me $\uparrow$

$(.5)$

[00:30:20.07] Interviewer: Ok.

$(1.0)$

[00:30:21.21] Kris: So yea (.) All of my: um (.) definitely like all of my close friends in Korea they know (.) now

Extract 4 focuses on the need for politeness in Korean culture, and how the concept of sexuality is not spoke about to 'elders'. The significance of this word, inflected and rising in intonation in each use, is important as shows the generational gap between Kris and the rest of the imagined Korean society. While not all elders in Korea embrace the 'conservative' nature that Kris describes, it is important for him to distinguish between them and those of his generation, who might be accepting of his sexuality. Also, he puts heavy emphasis on 'never and ever', repeating 'never' when talking about expressing sexuality in South Korea, slowing down his speech with pauses, but when talking about friends, speeding up his speech. This is noticeable in much of the interview, when he feels more 'free' to express his sexuality he usually speeds up his speech.

The next extract compares his initial traveling overseas, and how he was able to express his sexual identity in other countries.

\section{Extract 5}

[00:31:50.00] Interviewer: Alright (.) Alright (.) yea (.5) Um (.) so <when you're talking> uh:: (.) about your sexuality then= ho-how was it different when you traveled overseas as compared to being in Korea? $\downarrow$ (.) Did people seem to care more or less= or were you able to express yourself differently in different languages when you talked about it? $\uparrow$

[00:32:09.28] Kris: Uhm: (.) When I was in Europe (.) it was (.5) way much more easier $\uparrow$ (.) um (.) to be just open $\uparrow($.$) But >like in Romania when I was in Romania< (.) I (.) I didn't (.) feel like it was kind$ of like an open (.) or like gay friendly society at all $\uparrow$ (.) Because (.) $<$ I think that $>$ (.) it's kind of related with (.) countries (.) um (.) economy status $\uparrow$

$(0.5)$

[00:32:36.20] Interviewer: Ok 
[00:32:37.05] Kris: If you: (.) are in=I mean the richer (.) they're (.) they more (.) they accept you more $\downarrow$ (.) I think (.) that's how I think $\downarrow$

In Extract 5, Kris talks about traveling to Europe and Romania. From his speech, he constructs sexuality as reflective of a countries economic status. Where most countries in Europe that he traveled to (Spain, Italy, and France) were more accepting of his sexual identity, whereas places like Romania, with a lower economic status (as he described it), were less accepting. Extrapolating from this speech, Kris then is equating South Korea as a country with a developing economy, and therefore less accepting as more prosperous countries. The community he imagines then a one where more money equals greater acceptance. Paying attention to the inflections he uses when describing Romania ('all', 'status'), he appears to question his own thoughts, suggesting that what he says might not be true, but it is what he feels to be true; this is also supported by the heavy emphasis on ' $\mathrm{I}$ ' at the end of the excerpt.

Moving onward, Excerpt 6 provides a glimpse at how Kris felt to visit perhaps the most gay friendly city in the world, San Francisco.

\section{Extract 6}

[00:33:52.21] Interviewer: Alright (.) >So when you traveled to San Fran< (.) what was that like?

[00:33:54.18] Kris: It was (.) uh (.) like (.5) <Like I felt I could (.) really be who I am> (.) $\downarrow$ That's (.) um (.) the best: (.) >I don't know like how to express <=I think I could be much more who I am $\uparrow($. Like (.) without thinking anything like (1.0) I don't know (1.0) I don't know=I felt much more free(.) [Laughs]

Excerpt 6 is interesting as it has speech which is sped up through most of the response to the interviewer's question about being in San Francisco. This seems to match up with other instances of speech in the transcript where when Kris feels comfortable with a topic, he will speed up his response, with less pauses. Also, he laughs at the end, similar to how he addresses similar questions about being in Western countries where he could "(feel) much more free". Other phrases seem to confirm this, such as "really be who I am", and the use of the pronoun 'I' seems to indicate ownership of his sexuality in this context; compared to similar excerpts where describing sexuality in Korea seems to focus mostly on the second person. This seems to be a theme in the data as well, as I followed Kris from his arrival in Australia to when he left to go back to Korea.

Overall, expressions of sexual identity seem to be much easier for Kris to express when he is in a Western culture, supported both by the interview data and the data. This seems to match up with the literature from King (2008) and Dong-Jin (2001) when they found that their participants were more likely to express their sexuality when traveling. This brings us to the next theme in the data, making relationships with others.

\section{Making relationships}

The next collection of data focuses on making relationships with others, something King (2008) notices in his data as important since all of his participants tried to make relationships with others from Western Countries. 
Throughout the interview, Kris details who he made and maintained relationships with, explaining why he made them and whom he made them with as seen in Extract 7.

\section{Extract 7}

[00:37:43.02] Interviewer: So wh- why do you think that is?= That you (.) you only had um: (.) boyfriends from: (.) a different countries and not your own? $\uparrow$

(2.5)

[00:37:48.24] Kris: I:: (.) think that (.) I don't' know=It feels (1.0) I (.) I mean there are many guys that I= >not many but like $<$ (.) there were some guys that I (.) uh (.) that I had a crush on (.) in Korea $\downarrow$ (.) I mean they were Koreans=But like (.)I would never imagine myself like (.) dating $\uparrow$ with them because (.) first it's just so difficult in Korea=Second (.) I mean (.) you're not going to get married anyways (.) so what's the point of doing it? $\downarrow$

In Extract 7, Kris explains why none of his relationships were with other Koreans, but instead were with males from Western, mostly English speaking countries. Of note here is his explanation of why he would not date someone from Korea, with the words 'in' and 'dating' highly inflected, suggesting that the idea of getting into a relationship with someone in Korea would be problematic. This is supported from Dong-Jin's (2001) explanation that the laws in South Korea are of such a nature that those in the queer community find it hard to build relations with others as the Confucian model of family is ingrained in the culture. While Kris had several 'crushes' on other Koreans, he felt he could not pursue them as ultimately the law would not allow him to get married and form a strong and lasting relationship. Also, Kris's choice in language (English) and culture (Western) where he did seek out relationships pinpoint the need for Kris to find acceptance in his relationships outside of the Korean community at large. The idea of English being able to express more closely Kris's 'real' identity can be explained through his thoughts of English as a language of power.

\section{Language and Power}

Through the interview data, Kris was able to explain why he felt that English was a language where he could express himself in ways that Korean could not, showing how very real to him the conflicting identities he felt as a gay male living in South Korea. Extract 8 comes from near the end of the interview.

\section{Extract 8}

[00:40:18.12] Kris: I think it's because (.) um (.5) English is kind of like a global language right now and (.) at this point (.) Like everyone speaks English wherever you go= It's like the language you can (.) communicate with anyone in the world $\uparrow($.$) You (.) so (.) that's number one (.) And second I think$ that (.) America: (.) and: (.) well back in the past (.) well (.) the UK was kind of like the (.) the leading nation (.) his-historically $\downarrow$

$(1.0)$

[00:40:47.07] Interviewer:[ Right]

[00:40:47.07] Kris: [But] now (.) America is (.) um (.) the one who is leading the world $\uparrow($.$) so (.) um$ (.) I think that their: (.) economy (.) uh (.) status is definitely affecting the reason why people (.) study $\underline{\text { English }} \uparrow$ and why people are obsessed with (.) um (.) speaking it in Korea and using it (.) and: (.) Yea (.) I think that's the (.) main [reason]

Extract 8, while not focusing on sexuality in language use, shows why Kris thinks that English is a language of power, both within and without Korea. Once again, he 
mentions that English use is tied up with economic capital, and that those who speak English are better able to position themselves in jobs and society. His emphasis on 'English' near the end seems to put the word above speaking Korean, although the word itself is not spoken. This also points out once again that Kris feels as though Korea might be lower economically speaking, and that is why so many people try to learn English in Korea. Perhaps most interesting, while not explicitly stated in the data, is that if Korea gains a higher economic status, then maybe sexuality might not be as big as an issue as it is now as the culture of the English language is most often imported with the language with those who use it in daily practice.

\section{Discussions and Implications}

As with any research, the position of the researcher brings subjective realities to how he or she analyzes and orients themselves to the discourse. In this case, reading the literature surrounding queer issues in South Korea, definitions of sexuality, and trying to understand what it means to be queer in eastern cultures when in fact I am a straight identifying male from the West. This case study is well outside any current research I have conducted and therefore my own lens regarding gender studies is still quite new although I consider myself part of the queer movement. Therefore, this study has resulted in much introspection and while I feel I am able to understand the issues around sexuality in South Korea, it is something that is so removed from my own life that I hope I am able to present it in such a way that does more good than harm.

Across the data, I focused on expressions of sexuality within the interview data in an attempt to establish which language led Kris to express his 'real' identity, both inside and outside his home country. How he constructed his own subjective reality matched up nicely with the other very few studies into sexuality in the context of Korea, helping to support those claims. Kris's definition of his sexuality through the interview data verified this as well, and suggests that sexuality is most certainly defined differently in language and culture.

As far as the implications of this study, it is related to those who might be interested in gender studies, as well as those who seek to understand how students or participants in a study express themselves differently on an online environment by examining identity markers in a subjective manner which allows them to see how it evolves through time and space. For example, Bucholtz and Hall (2004) pay attention to the desire-centered view of sexuality, which suggests that sexuality is not something then that is as easily defined as simple romantic attraction to another, but is also contingent on language, society, and desire to fit into a community (real or imagined).

Therefore, researchers should take a subjective approach to the subject of sexuality and realize that it should be defined by the individual, not as an objective 'truth' of stable identity. The chore of future research then would be to examine constructs of identity as being situated through the desire, of course, of the individual, but also examining how that desire shifts through language selection and use in context. Additionally, if the focus on sexuality serves but as one identity marker, it is also fair, and expected, that the opportunity for examining other identity markers in similar studies would help to construct in what ways sexuality is challenged or normalized in others instances of speech 
or text. As a final point, what this study finds then is that the interpretation of sexuality is bound in the subjective (lived experience of the individual), while always competing with the presumably objective truth of social and cultural practices.

\section{References}

Anderson, B. (1991). 1991: Imagined Communities: Reflections on the Origin and Spread of Nationalism. Revised Edition. London and New York: Verso.

Blackburn, M. (2005). Agency in borderland discourses: Examining language use in a community center with black queer youth. The Teachers College Record,107(1), 89 113.

Benwell, B., \& Stokoe, E. (2006). Discourse and identity. Oxford University Press.

Bourdieu, (1991). Language \& symbolic power. Cambridge, MA: Harvard University Press.

Bucholtz, M., \& Hall, K. (2004). Theorizing identity in language and sexuality research. Language in Society, 33(04), 469-515.

Cameron, D. (2005). Language, gender, and sexuality: Current issues and new directions. Applied Linguistics, 26(4), 482-502.

Cameron, D., \& Kulick, D. (2003). Language and sexuality: Cambridge, MA: Cambridge University Press.

Creswell, J. W. (2008). Research design: Qualitative, quantitative, and mixed methods approaches. Sage publications.

Dong-Jin, S. (2001). Mapping the vicissitudes of homosexual identities in South Korea. Journal of Homosexuality, 40(3-4), 65-78.

Duff, P. A., \& Uchida, Y. (1997). The negotiation of teachers' sociocultural identities and practices in postsecondary EFL classrooms. Tesol Quarterly,31(3), 451-486.

Eckert, P., \& McConnell-Ginet, S. (1992). Think practically and look locally: Language and gender as community-based practice. Annual Review of Anthropology, 461-490.

Foucault, M. (1978). The history of sexuality, volume 1: An introduction (R. Hurley, Trans.). New York, NY: Vintage.

Huffaker, D. A., \& Calvert, S. L. (2005). Gender, identity, and language use in teenage blogs. Journal of Computer-Mediated Communication, 10(2), 00-00.

Ipsos. (2013). Global @dvisor: Same-Sex Marriage. Retreived from http://www.ipsosna.com/download/pr.aspx?id=12795

Jacobs, G. (1996). Lesbian and gay male language use: A critical review of the literature. American Speech, 49-71.

Jackson, J. (2014). Introducing language and intercultural communication. New York, NY: Routledge

Jørgensen, M. W., \& Phillips, L. J. (2002). Discourse analysis as theory and method. Sage. 
King, B. W. (2008). "Being gay guy, that is the advantage": queer Korean language learning and identity construction. Journal of Language, Identity, and Education, 7(3-4), 230252.

Norton, B. (2000). Identity and language learning: Gender, ethnicity and educational change (pp. 2000-2000). London: Longman.

Norton, B., \& Pavlenko, A. (2004). Addressing gender in the ESL/EFL classroom. TESOL Quarterly, 38(3), 504-514.

Norton, B. (2013). Identity and language learning: Extending the conversation, $2^{\text {nd }}$ Edition. Bristol, UK: Multilingual Matters. 